\title{
Black/White Cancer Survival Study
}

National Cancer Institute

\section{Source}

National Cancer Institute. Black/White Cancer Survival Study. NCI Thesaurus. Code C16067.

A study designed to investigate the significance of social, behavioral, lifestyle, biological, treatment, and health care factors in relation to the observed differences in cancer survival between African-Americans and white Americans. Data was collected on more than 3,400 patients, focusing on cancers of the breast, colon, uterus, and bladder. 